\title{
Eco-Impact of Shopping Bags: Consumer Attitude and Governmental Policies
}

\author{
$\mathrm{Yi} \mathrm{Li}$ \\ Institute of Textiles and Clothing, The Hong Kong Polytechnic University \\ Hung Hom, Kowloon, Hong Kong, China \\ Tel: 852-2766-6479 Fax: 277314321 E-mail: tcliyi@inet.polyu.edu.hk \\ Subramanian Senthilkannan Muthu \\ Institute of Textiles and Clothing, The Hong Kong Polytechnic University \\ Hung Hom, Kowloon, Hong Kong, China \\ E-mail: senthilkannan@gmail.com \\ J.Y. Hu \\ Institute of Textiles and Clothing, The Hong Kong Polytechnic University \\ Hung Hom, Kowloon, Hong Kong, China \\ E-mail: tcjxhu@polyu.edu.hk \\ P.Y. Mok \\ Institute of Textiles and Clothing, The Hong Kong Polytechnic University \\ Hung Hom, Kowloon, Hong Kong, China \\ E-mail: Tracy.Mok@inet.polyu.edu.hk \\ Xuemei Ding \\ College of Fashion, Donghua University, Shanghai, China- 200051 \\ E-mail: ding.x.6@googlemail.com \\ Laili Wang \\ College of Fashion, Donghua University, Shanghai, China- 200051 \\ E-mail:wanglaili@sina.com \\ Weibang Chen \\ College of Fashion, Donghua University, Shanghai, China- 200051
}

This research work is financially supported by The Hong Kong Polytechnic University through project RP7Q.

\begin{abstract}
Shopping bags are a symbol of the throw-away society, its deliberation on eco-impact is reasonably high compared to other products. Life cycle assessment (LCA) is used to throw light on the eco-impact of non-woven and woven bags. Life Cycle Assessment comprises of different stages of a product, from its manufacturing phase to end-of-life phase. Government and consumers are accountable primarily for the end of life phase covering reuse, recycle and disposal to landfill. The consumer plays a vital role here in terms of opting between the usage and disposal criteria which alleviates eco-impact and also the government assumes significant importance in providing the appropriate recycling strategies and policies. In this research work, an attempt has been made to elicit the consumer's attitude towards reuse, recycle and disposal to landfill options and to elucidate the existing governmental policies on recycling as well as willingness of people to support them by means of a research questionnaire survey conducted in China, Hong Kong and India, amongst different user groups of various shopping bags.
\end{abstract}

Keywords: Human behaviour, Policy dimensions, Reuse, Recycle, Landfill, Shopping bags

\section{Introduction}

The disposal phase of any product attracts more importance in terms of its eco-impact compared to other phases in its entire life cycle. The same is also applicable to shopping bags. Human dimensions in consumer behaviour rule the decision of a product's disposal phase and consequently the eco-impact. Apart from human dimensions, governmental policies also assume significant importance in the environmental impact. This phenomenon is explained in detail by the study of eco-impact of various shopping bags in this current article.

The current trend of shopping bags preferred by consumers in the market can be categorized into 4 groups namely plastic, paper, woven and non woven bags according to the manufacturing technology and raw materials used. A plentiful array of raw materials, styles, designs are being employed to manufacture them which makes the sub types of shopping bags into an endless list (Subramanian Senthilkannan Muthu, etal., 2009, pp.307-320).Ecological concerns are growing at high speed. People have started to look for eco-friendly/green 
products everywhere (Subramanian Senthilkannan Muthu, etal, 2008, pp.102-109). People's concern on environment, along with the levies/ stringent rules imposed by the government on non-eco friendly products, is causing ecological concerns to reach pinnacle of importance.

There has been a dearth of research articles published on the subject of shopping bags as a whole. The only article published so far on consumer perception of shopping bags written on the basis of the attributes of shopping bags, is restricted to plastic and paper bags (Gerard Prendergast, etal, 2001, pp. 475-482). To fill these knowledge gaps, this article focuses on the consumer's perception and behavior on the usage and disposal of various shopping bags (frequency of reuse, recycle of different shopping bags and also their propensity to dispose these to landfills) and also investigates the existing policy dimensions of government on recycling phase and other associated factors related to it. The discussion in this article is also confined to different types of shopping bags, such as plastic, paper, non-woven and woven bags.

Another important aim of this article is to enable us to construct end-of-life scenarios in Life Cycle Assessments (SETAC workshop report (1992), SETAC (1990), ISO 14040(1997), ISO 14041(1998), ISO 14042(2000), ISO 14043(2003)) by using real values from the actual users of shopping bags. The Life Cycle Assessment of a product assumes greater significance in determining the eco-friendliness of the product. How a product is disposed assumes equal significance as how a product is manufactured. Some of the previous studies conducted in this area to determine the life cycle of shopping bags (Rae Dilli (2007), Los Angeles County Department of Public Works (2007), NOLAN-ITU Pty Ltd (2002)) used an assumption which is very distant from reality. Hence to determine the attitude of users of shopping bags and to understand the disposal scenarios, a questionnaire survey was conducted in China, Hong Kong and India among different user groups of shopping bags. These three countries were particularly chosen, since the authors are from these countries and they intend to create awareness and consequently educate people of the country to which they belong to.

\section{Design of the present research work}

Figure 1 illustrates the whole structure of this research work. A huge amount of data is required in each phase of a product to perform Life Cycle Assessment. LCA covers different aspects of a product from its manufacturing state to its disposal state. Data in terms of the quantity of raw materials required, energy needs, and amount of pollutants and wastes emitted, etc. are needed in each phase of a product to study the complete life cycle of a product. As depicted in Fig.1, the data related to manufacturing, transportation and distribution phases can be obtained from the group of manufacturers through direct observation of manufacturing process or data collection through surveys or by interviewing the responsible staff or by secondary data from previous studies/ literature.

But when it comes to the usage and disposal phases, the data should come from the actual users as human and policy dimensions play a crucial role here. Understanding of human and policy dimensions, which decide the use and end-of-life scenarios of different types of shopping bags, is essential to understand the eco-impact made by them. This research study utilized this survey as a means to decipher them, which is discussed in detail here.

\section{Vision of the survey}

As stated earlier, the aims of the survey lies in comprehending the usage and disposal behaviors of different types of shopping bags under discussion amongst different user groups. Usage and disposal behaviors are defined as how many times people reuse different shopping bags, what percentage of shopping bags can be recycled/ sent to landfill with the existing possibilities of recycling in their own country and what percentage of shopping bags people perceive can be reused/recycled/sent to landfill. Also this survey intends to comprehend the existing recycling options provided by the government and the willingness of people to support the government's policies further to improve the possibilities of recycling. This article reports the survey responses from different user groups of China, Hong Kong and India.

\section{Respondents of research questionnaire survey}

This survey was accomplished among students, home makers, employed professionals in various fields of different age groups, who are users of shopping bags and also have knowledge about their usage and disposal behaviour in the countries under discussion. This survey was mainly aimed at understanding the consumer's perception of reuse, recycle and disposal to landfill, recycling possibilities with the existing government provisions/policies for recycling, willingness to support recycling systems/policies to reduce the percentage of landfill and so on. Convenience sampling method was chosen for this study and the survey was answered by 100 respondents from China and 125 respondents from India and Hong Kong. Respondents were contacted by electronic means and also in person. This survey had 9 questions pertaining to the usage and disposal of shopping bags and 4 questions pertaining to the personal particulars of respondents (refer Appendix).

\subsection{Demographic Profiles of Respondents of Survey}

Personal particulars of the respondents from the three countries chosen for this study are shown in the following Figs.2-5. Fig.2 illustrates the age of respondents of survey, from which it can be understood that the majority of the respondents fall in the age group of 21-30 years in all the three countries under discussion. The gender of respondents can be found from Fig.3, where it can be seen that the majority of the respondents are females in 
China and Hong Kong and in India the majority of respondents are males. Fig. 4 describes the profession of respondents. In China and India, the majority of the respondents are employed in various professions and in Hong Kong, the majority of the respondents are students. Fig.5 portrays the educational qualifications of respondents who answered the survey conducted for this research work. In China and India, the majority of the respondents holds post graduate degree and in Hong Kong majority of the respondents hold undergraduate degrees. This shows the major limitation of this study, apart from less number of responses obtained; the demographic profile of the respondents is biased between the young and educated population.

However, sampling the young and educated respondents could indicate future trends in Asia. A large scale survey of the mass population in the selected countries for this study is needed to reveal their true behaviors.

\section{Usage and Disposal behavior of Shopping Bags}

There are three major aspects in this investigation. They are:

Reusability

Recyclability

Disposal to Landfill

\subsection{Reusability}

The concept of reusability can be defined in two ways. One usual way is reuse of the product as a different one instead of discarding it into waste. For example, used non-woven bags can be reused as liners/ supportive covers in dust bins. The second way of defining reusability, which is usage of the particular product for the same purpose for which it is originally intended till it reaches its end of life or discarding stage i.e. simply use the same product many times. Basically this is imperative since it postpones the stage of discarding and it delays the start of a new product while the first one is still in the stage of being used. The first one also holds good as far as dumping in landfill sites in the early stages is concerned. Even then, the second category deserves considerable appreciation since it is linked to the economy of an individual, along with the benefits already discussed. Therefore, it is the responsibility of manufacturers to employ suitable raw materials and manufacturing technology for a shopping bag to be reused many times, and it the responsibility of users to reuse the bag many times till it can be discarded.

\subsection{Recyclability}

This refers to the conversion of discarded ones after use into new products. This process involves breaking down the old items and producing the new products. This helps in the diminution of wastage of materials which has the potential to be used again and to trim the consumption of fresh raw materials and other associated benefits of reduced cost, energy, pollution, etc. Here the government is accountable for providing policies/provisions which enable people to be motivated to opt for recycling of products rather than directly disposing them to landfill. However no one can deny the fact that in spite of governmental policies, public participation also matters greatly in augmenting the proportion of recycling.

\subsection{Disposal to Landfill}

A landfill site is the final destination of all products once they can no longer be used. It is a place for the disposal of waste/garbage by interment. This is the origination of many problems pertaining to ecological problems like pollution of water and air, etc. A major proportion of aspiration of eco- friendliness lies in the prevention of early entry of any product into landfill till it becomes completely useless.

\section{Results \& Discussion}

As discussed earlier, this survey was conducted among different user groups in China, Hong Kong and India. The results obtained are discussed below.

\subsection{Reusability of shopping bags}

Figs. 6-7 exemplify the reusability of different types of shopping bags from the survey results. Fig. 6 shows how many times respondents reuse plastic bags, from which it is clear that the respondents from China and Hong Kong prefer to use plastic bags twice and the Indians 3-5 times. Fig.7 illustrates the reuse of paper bags, Chinese respondents desired to use paper bags for 3-5 times and people from Hong Kong and India preferred twice and once respectively. Fig. 8 shows how many times respondents reuse non-woven bags, from which it is clear that the respondents from China, Hong Kong and India prefer to use non-woven bags 3-5 times. From Fig.9, which illustrates the reuse of woven bags, respondents in China and India chose to use woven bags $>5$ times and respondents from Hong Kong for 3-5 times and respectively. These results portray a mixed behaviour, which will not be appropriate to represent the actual reuse values of both bags. It is essential to calculate an effective percentage of reuse which is a reflection of all values represented here.

Hence two equations were framed to calculate the potential reuse of shopping bags. In equation 1 , the corresponding percentage of $<1$ and 1 time usage is considered as $100 \%$ and 2 Times as $50 \%$ and 3-5 times as $25 \%$ and others ( $>5$ times) is on an average considered to be $10 \%$. 
$\rho=$ Total Disposal $\%=\mathrm{P}_{0} * 100 \%+\mathrm{P}_{1} * 100 \%+\mathrm{P}_{2} * 50 \%+\mathrm{P}_{3} * 25 \%+\mathrm{P}_{4} * 10 \%$

Reuse $\%=100-\rho$

Where $\mathrm{P}_{0}$ is the percentage of reuse for $<1$ time and so on. Please refer to Figs. 2-3 for the definitions of other indices.

Fig. 10 illustrates the effective percentage of reuse values of non-woven and woven bags of the three countries. From Fig. 8, it is understood that on comparative grounds, woven bags are preferred much to be reused more number of times than the other bags.

\subsection{Percentage of the shopping bags that can be recycled with the existing recycling possibilities provided by government}

The second part of this survey attempts to determine the percentage of recycling of shopping bags possible with the existing recycling options available in China, Hong Kong and India. The survey results are presented in Figs.11-14. Fig.11 presents the recycling possibilities existing for plastic bags and Fig 12 for paper bags. At the maximum $10 \%$ of plastic bags and $50 \%$ of paper bags can be recycled in all countries listed here. Fig. 13 depicts the recycling possibilities existing for non-woven bags and Fig 14 for woven bags. At the maximum, 21-30\% of non-woven bags can be recycled in China, 31-50\% in Hong Kong and 21-30\% in India. Similarly for woven bags, at the maximum, 31- 50\% in China, Hong Kong and India can be recycled. Again, it is necessary to have an effective recycling percentage represented by the values in all categories, which was derived by weighted average method and presented in Fig. 15.

Fig. 15 shows that a maximum of $22 \%$ of plastic bags and $31 \%$ of paper bags can be recycled with the existing possibilities. The case is reverse when compared to reuse behaviour here. People prefer more to recycle paper bags than plastic bags. Actually the potential recycling rate of plastic bags is less than paper bags, the reason for the same needs to be investigated in detail. Also $22 \%$ of non-woven bags in China, $25 \%$ in Hong Kong and $21 \%$ in India as well as $20 \%$ of woven bags in China, $23 \%$ in Hong Kong and $27 \%$ in India can be recycled with the existing possibilities.

\subsection{Percentage of shopping bags can be recycled/ reused/sent to landfill}

This part of the survey covers the response from the respondents to understand what percentage of shopping bags people perceive can be sent to recycle/reuse/sent to landfill. The results in this category for plastic and paper bags described below in Fig.16 and Fig.17 exemplifies the same for non-woven and woven bags. These results can be directly employed for disposal scenarios while performing the life cycle analysis of different shopping bags, which is the main part of this survey.

\subsection{Provision of recycling system/policy by government}

Fig.18 reveals the provision of recycling systems in India, Hong Kong and China. In all these countries, respondents voted maximum for provision of recycling systems in their respective countries. Even though a majority of the respondents voted for provision of recycling systems, some said that there is no provision of recycling systems. This finding which may be due to the ignorance of the respondents or the existing systems may not fulfill their expectations. This needs to be further investigated.

\subsection{Willingness of people to support recycling policy / system to reduce the landfill percentage}

In spite of government's efforts, the willingness of the people to support recycling system/policy matters a great deal to address environmental issues effectively. Fig.19 describes the results derived in this category. Respondents from China and Hong Kong are $100 \%$ willing to support recycling system/policy, but only $95 \%$ of Indians are willing to support the system. Though it is a very negligible amount, taking into account the sample size, people in India need to be educated about eco-systems and impacts.

\subsection{Forwarding of used shopping bags to recycling bins provided}

This section describes the willingness of respondents to keep shopping bags in the recycling bins provided by the government. The results derived from China, Hong Kong and India are given in Fig.20. 95\% of respondents from China are willing to place the used bags in bins and those from Hong Kong \& India show a 97\% willingness in this regard. The remaining 5\% of respondents from China and 3\% of respondants in Hong Kong and India need to be brought to 'Yes' category by means of educating them on the importance of recycling.

\section{Conclusion}

This research article reported the usage and disposal behavior of consumers of shopping bags in China, Hong Kong and India. The results from this survey represent realistically the attitudes and behaviors of young, educated consumers. Hence these results may be employed in Life cycle assessment modeling of shopping bags in preference to inappropriate assumptions which do not represent the real picture. It is the joint venture of individuals and government to rigorously work for optimum usage and disposal scenarios, to reduce the environmental impact made by shopping bags. The usage and disposal scenario of different types of shopping bags assume significance over other products, since these bags are professed to be a symbol of throw-away 
society, where the eco-concerns are more. It is imperative and logical to study the eco-impact of shopping bags with survey results which come from the consumers who are the actual users.

\section{Acknowledgements}

The authors are grateful to The Hong Kong Polytechnic University for providing funding support to this research through project RP7Q and to all the respondents to the survey conducted in China, India and Hong Kong.

\section{References}

Prendergast, G., Ng, S.W. \& Leung, L.L. (2001). Consumer perceptions of shopping bags, Marketing Intelligence \& Planning, 19(7), 475-482.

ISO 14040. (1997). Environmental management- life cycle assessment-principles and frame work, Geneva: International Organisation for Standardisation.

ISO 14041. (1998). Environmental management-life cycle assessment- goal and scope definition and inventory analysis. Geneva: International Organisation for Standardisation.

ISO 14042. (2000). Environmental management- life cycle assessment-life cycle impact assessment. Geneva: International Organisation for Standardisation.

ISO 14043. (2003).Environmental management-life cycle assessment-life cycle interpretation. Geneva: International Organisation for Standardisation.

Los Angeles County Department of Public Works. (2007). An Overview of Carryout Bags in Los Angeles County, August 2007, [Online] Available: http://ladpw.org/epd/pdf/PlasticBagReport.pdf. (June 1, 2009)

NOLAN-ITU Pty Ltd. (2002). Non-woven Shopping Bags - Analysis of Levies and Environmental Impacts, Final Report, Victoria, Australia, December 2002, [Online] Available: http://www.environment.gov.au/settlements/publications/waste/plastic-bags/pubs/analysis.pdf. (June 7, 2009)

Dilli, R. (2007). Comparison of existing life cycle analysis of shopping bag alternatives, Final report, Hyder Consulting Pty Ltd, Australia, April [Online] 2007, Available: http://www.sustainability.vic.gov.au/resources/documents/LCA_shopping_bags_full_report[2].pdf (June 7, 2009)

SETAC workshop report (1992). A conceptual framework for Life-Cycle Impact Assessment, James Fava, etal, (Eds.) February 1-7, USA, 1992.

SETAC (1990). A Technical Framework for Life Cycle Assessment, Edited by: James A Fava, etal, August 18-23, Smugglers Notch, Vermont, 1990.

Muthu, S.S.K., Li, Y., Hu, J.Y., \& Mok, P.Y. (2009). An Exploratory Comparative Study on Eco-Impact of Paper and Plastic Bags, Journal of Fibre Bioengineering and Informatics, 1.4, 307-320.

Muthu, S.S.K., Li, Y., Hu, J.Y., \& Mok, P.Y. (2008). Eco-Friendly Fibers for Sportswear, Proceedings of TBIS 2008, 14-16 August 2008, Hong Kong, pp.102-109. 


\section{Appendix:}

\section{Survey Questionnaire:}

Dear Reader,

We are doing a study on environmental impact of grocery shopping bags (such as those used in supermarkets and/or street markets), which becomes a critical issue. Your views are extremely important. We are very much grateful if you could contribute to this issue by answering the following questions. Please $(\sqrt{ })$ tick the selected option of yours or highlight your selected option in bold letters if you want to send it back to us in electronic format. Kindly send it back to: senthilkannan@gmail.com

\begin{tabular}{|c|c|c|c|c|c|c|}
\hline 1. & $\begin{array}{l}\text { How many times do you reuse a } \\
\text { non-woven bag? }\end{array}$ & $<1$ time & 1 time & 2 times & $3-5$ times & Others \\
\hline 2. & $\begin{array}{l}\text { How many times do you reuse a woven } \\
\text { bag? }\end{array}$ & $<1$ time & 1 time & 2 times & 3-5 times & Others \\
\hline 3. & $\begin{array}{l}\text { How many times do you reuse a nonwoven } \\
\text { (Polypropylene) shopping bag? }\end{array}$ & $<1$ time & 1 time & 2 times & $3-5$ times & Others \\
\hline 4. & $\begin{array}{l}\text { How many times do you reuse a } \\
\text { woven/cloth shopping bag? }\end{array}$ & $<1$ time & 1 time & 2 times & 3-5 times & Others \\
\hline 5. & $\begin{array}{l}\text { What \% of the shopping bags do you think } \\
\text { that can be recycled with the existing } \\
\text { recycling possibilities provided by } \\
\text { government: } \\
\text { Non-woven Bag: } \\
\text { Woven Bag: } \\
\text { Nonwoven bag: } \\
\text { Woven / Cloth Bag: }\end{array}$ & $\begin{array}{l}1-10 \% \\
1-10 \% \\
1-10 \% \\
1-10 \%\end{array}$ & $\begin{array}{l}11-20 \% \\
11-20 \% \\
11-20 \% \\
11-20 \%\end{array}$ & $\begin{array}{l}21-30 \% \\
21-30 \% \\
21-30 \% \\
21-30 \%\end{array}$ & $\begin{array}{l}31-50 \% \\
31-50 \% \\
31-50 \% \\
31-50 \%\end{array}$ & $\begin{array}{l}\text { Others } \\
\text { ( Pls specify) }\end{array}$ \\
\hline 6. & $\begin{array}{l}\text { What \% of the shopping bags do you think } \\
\text { that can be Recycled/ Reused/Sent to } \\
\text { Landfill: } \\
\text { Non-woven Bag: } \\
\text { Woven Bag: } \\
\text { Nonwoven bag: } \\
\text { Woven / Cloth Bag: }\end{array}$ & $\begin{array}{l}\text { Recycle } \\
\%\end{array}$ & $\begin{array}{l}\text { Reuse } \\
\%\end{array}$ & $\begin{array}{l}\text { Landfill } \\
\%\end{array}$ & $\begin{array}{l}\text { Total } \\
100 \% \\
100 \% \\
100 \% \\
100 \%\end{array}$ & \\
\hline 7. & $\begin{array}{l}\text { Currently does your government provide } \\
\text { recycling system/ policy? }\end{array}$ & Yes & No & & & \\
\hline 8. & $\begin{array}{l}\text { If your government sets up a recycling } \\
\text { policy / system to reduce the landfill } \% \text {, are } \\
\text { you willing to support? }\end{array}$ & Yes. & No. & & & \\
\hline 9. & $\begin{array}{l}\text { Would you like to place the used shopping } \\
\text { bag to the recycling bins provided by your } \\
\text { government? }\end{array}$ & Yes. & No. & & & \\
\hline
\end{tabular}

Any other Comments:

Personal Details: (Please underline your selected option)

Age: $\quad<21 ; 21-30 ; 30-40 ; 40-50$; >50 Yrs;

Gender: Male / Female;

Profession: Student / Housewife/ Employed/ others;

Education level: Primary school/ Secondary school/ University level/ Postgraduate level/ others

Country: ; Place:

Thank you very much for your precious time spent in filling up this questionnaire. 


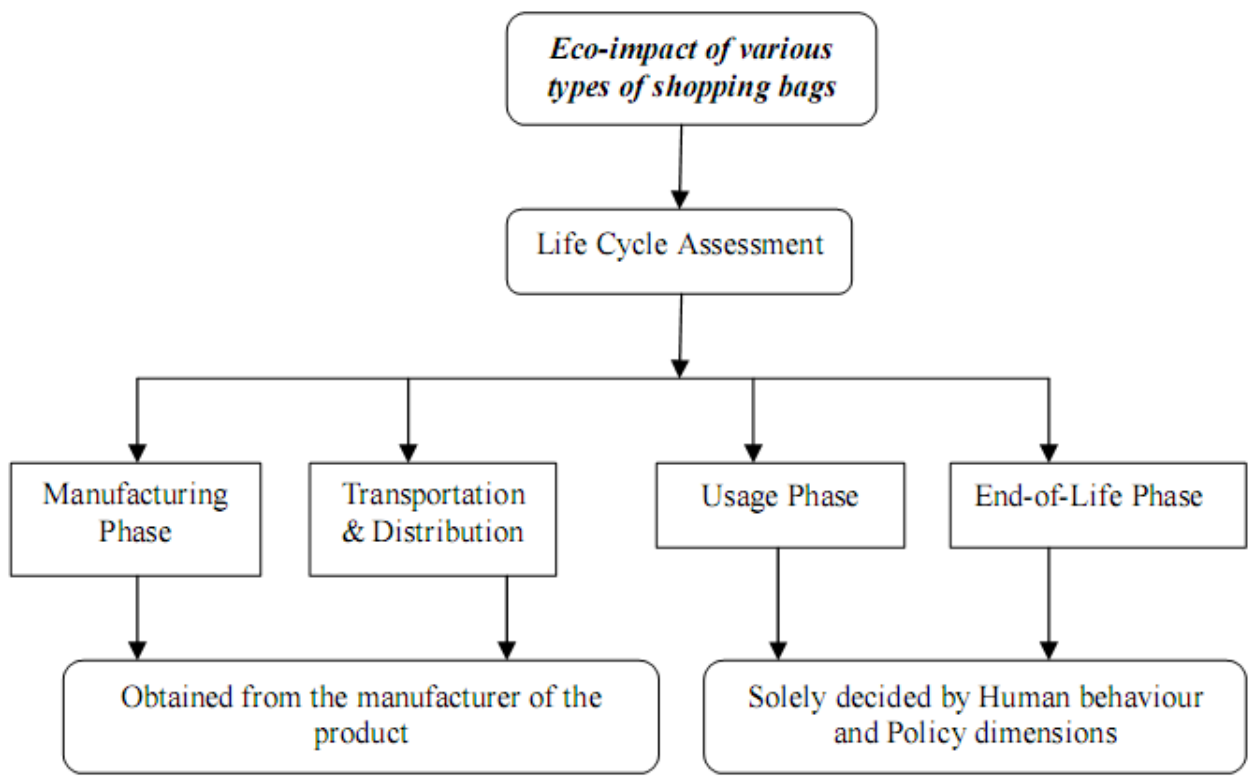

Figure 1. Design of the current study

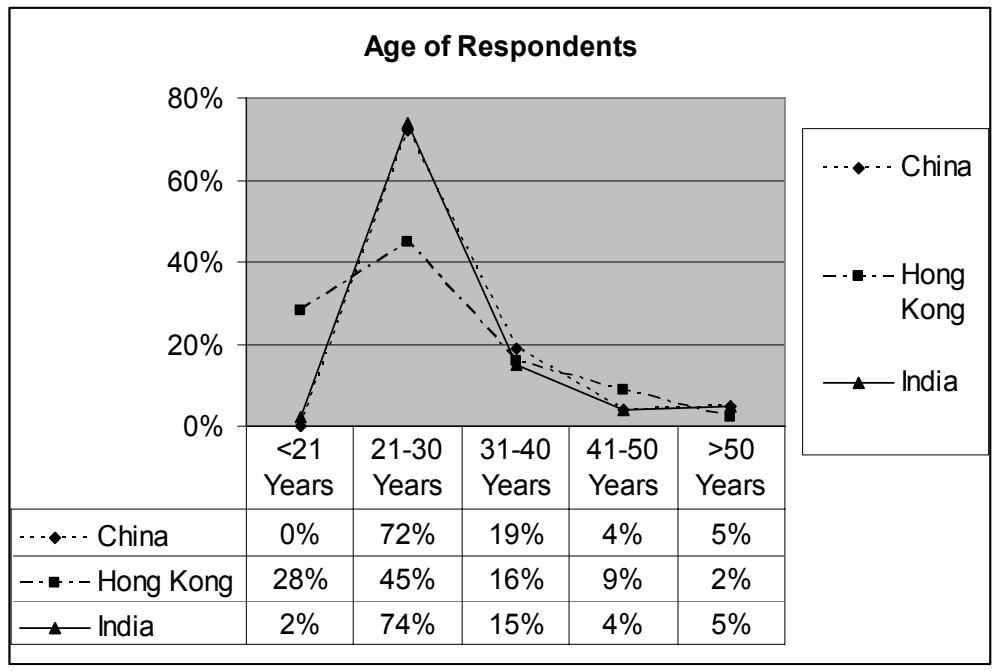

Figure 2. Age of Respondents

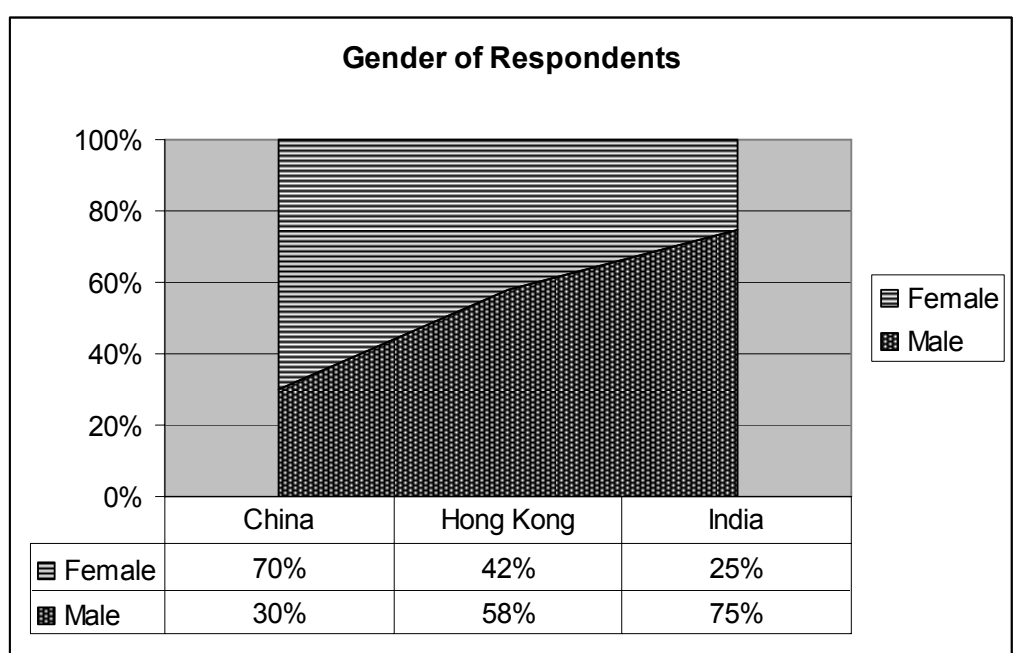

Figure 3. Gender of Respondents 


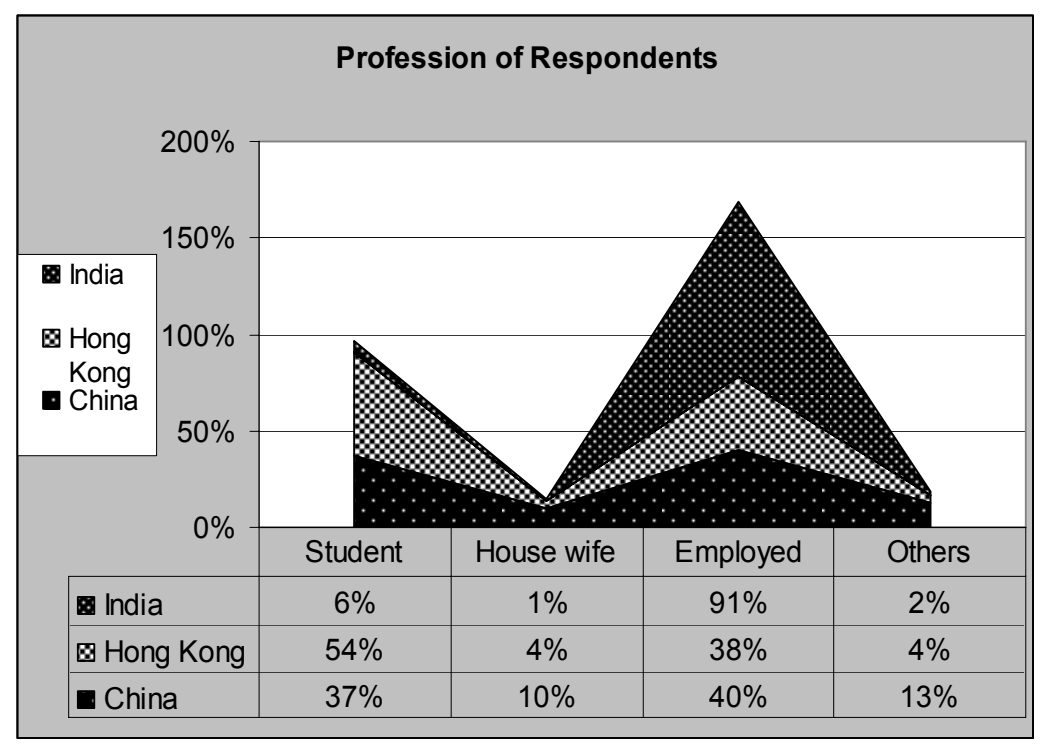

Figure 4. Profession of Respondents

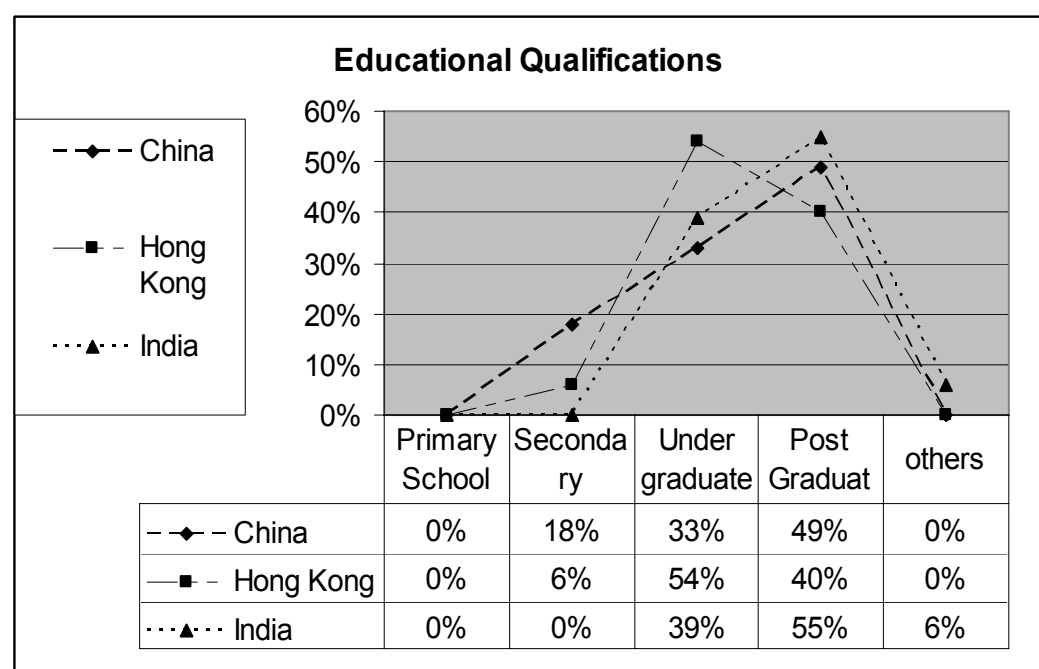

Figure 5. Educational Qualifications of Respondents

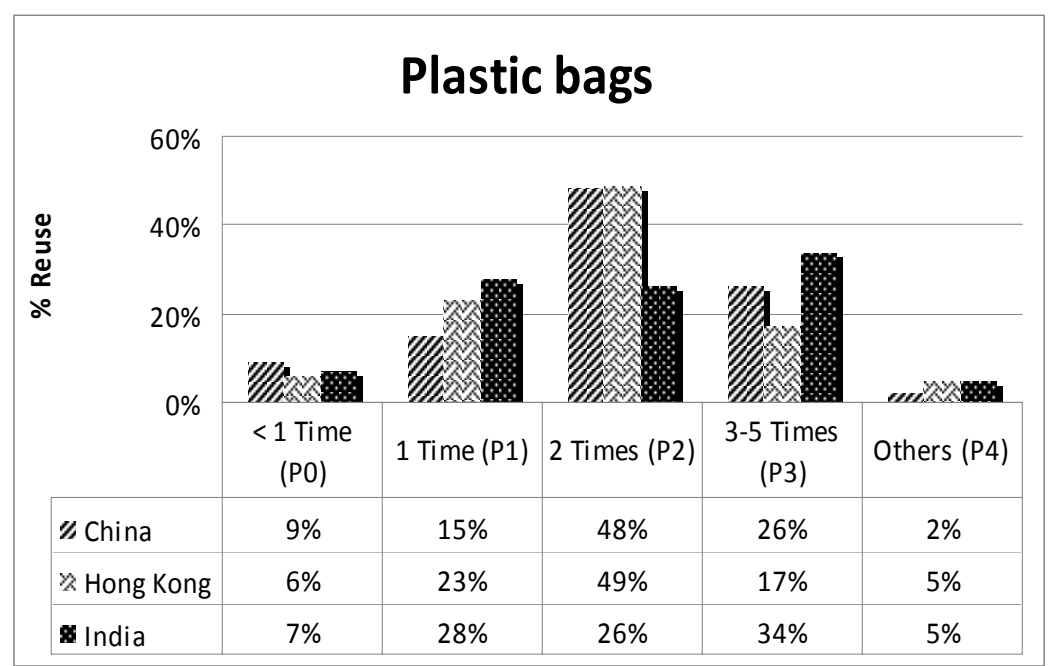

Figure 6. Reusabiltiy of plastic bags 


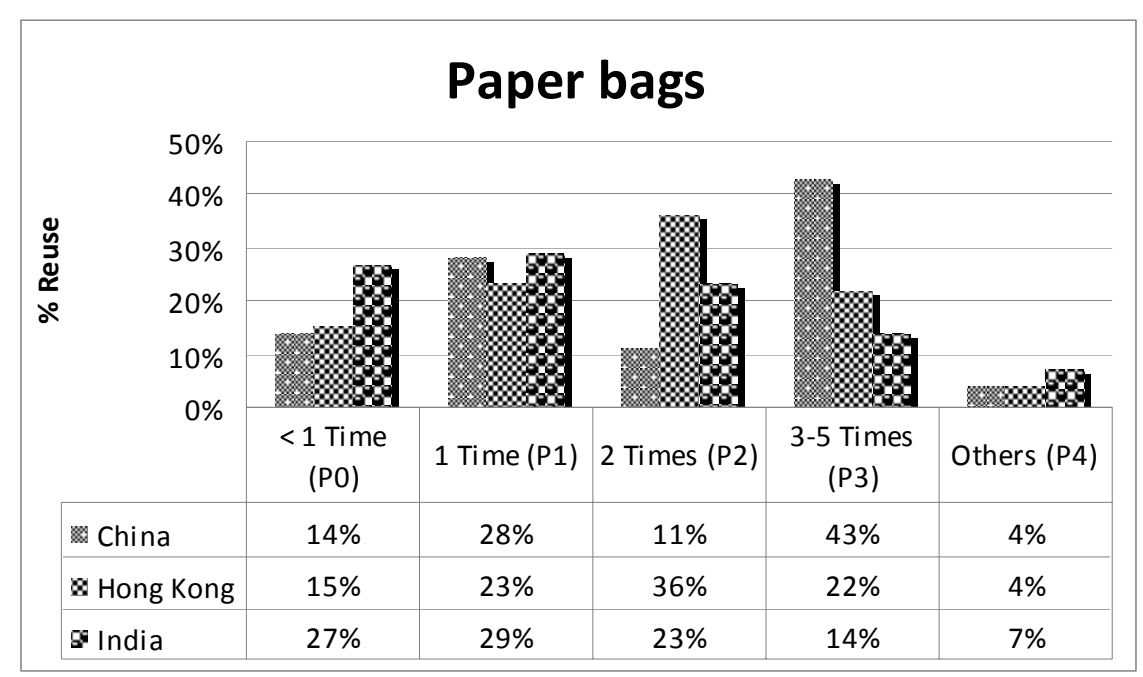

Figure 7. Reusabiltiy of paper bags

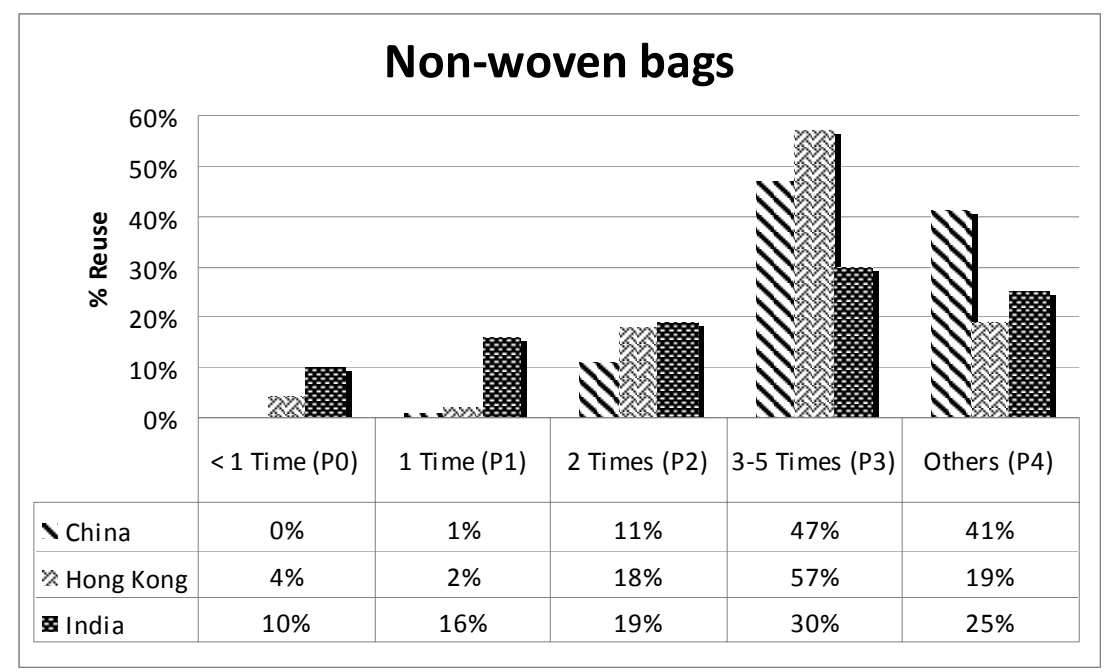

Figure 8 . Reusabiltiy of non-woven bags

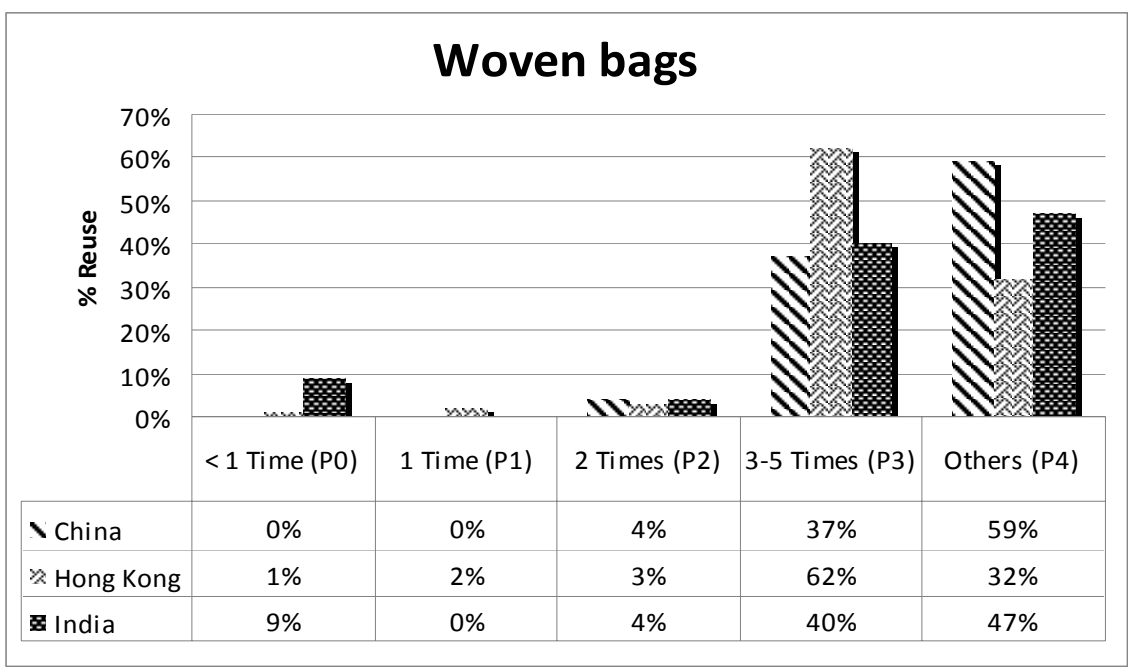

Figure 9. Reusabiltiy of woven bags 


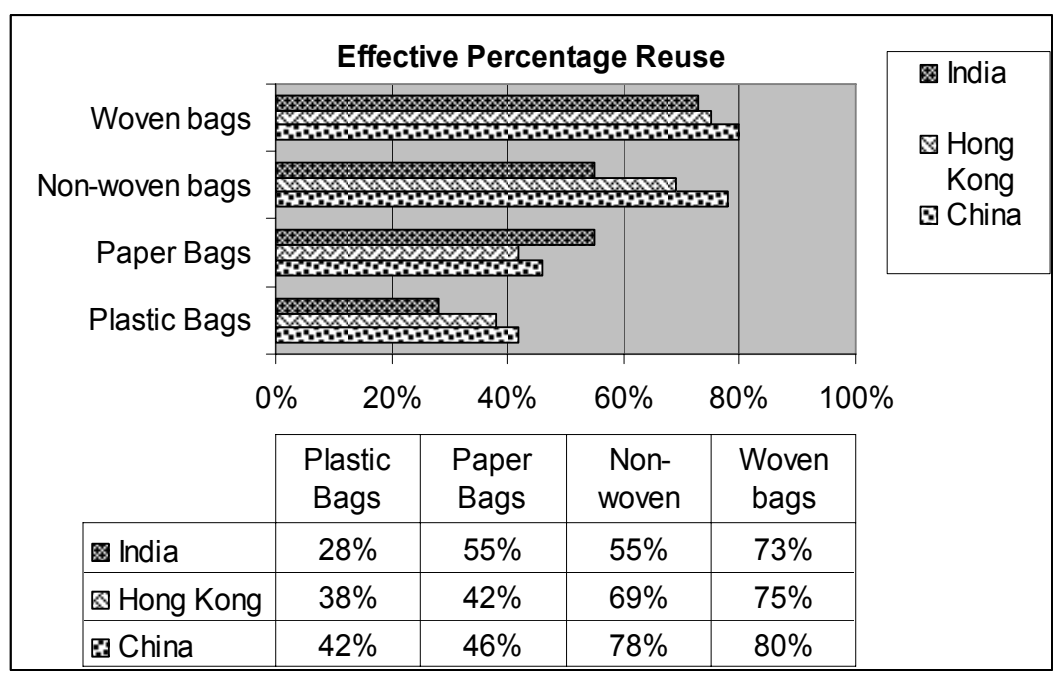

Figure 10. Effective percentage of reuse

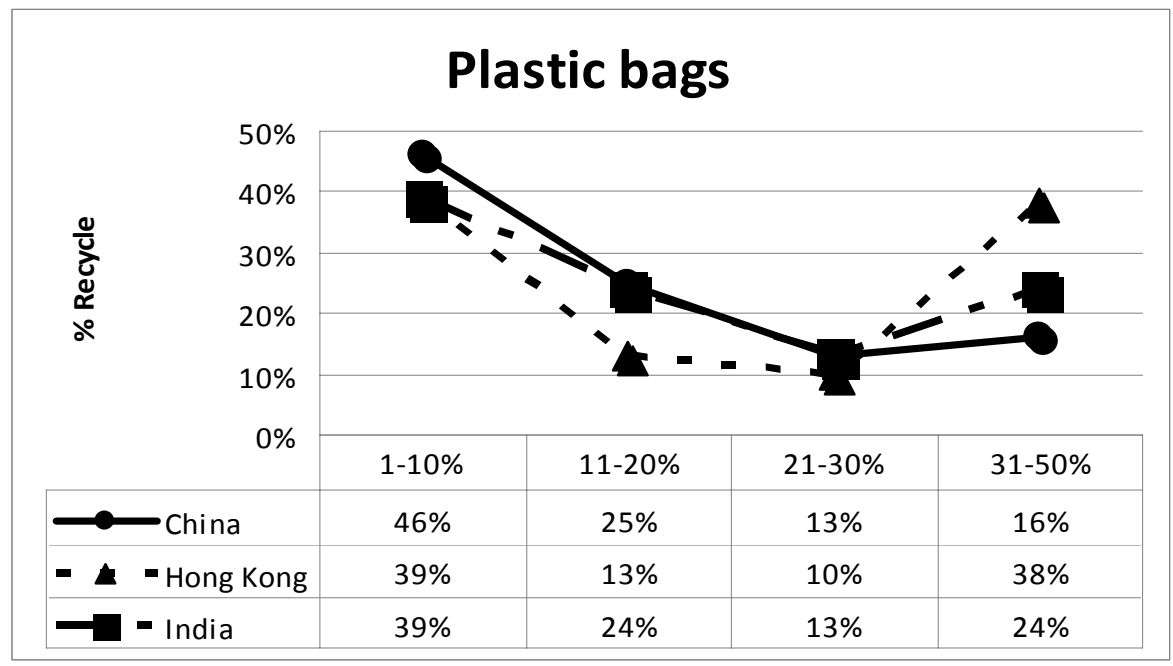

Figure 11. Percentage of recycling of plastic bags

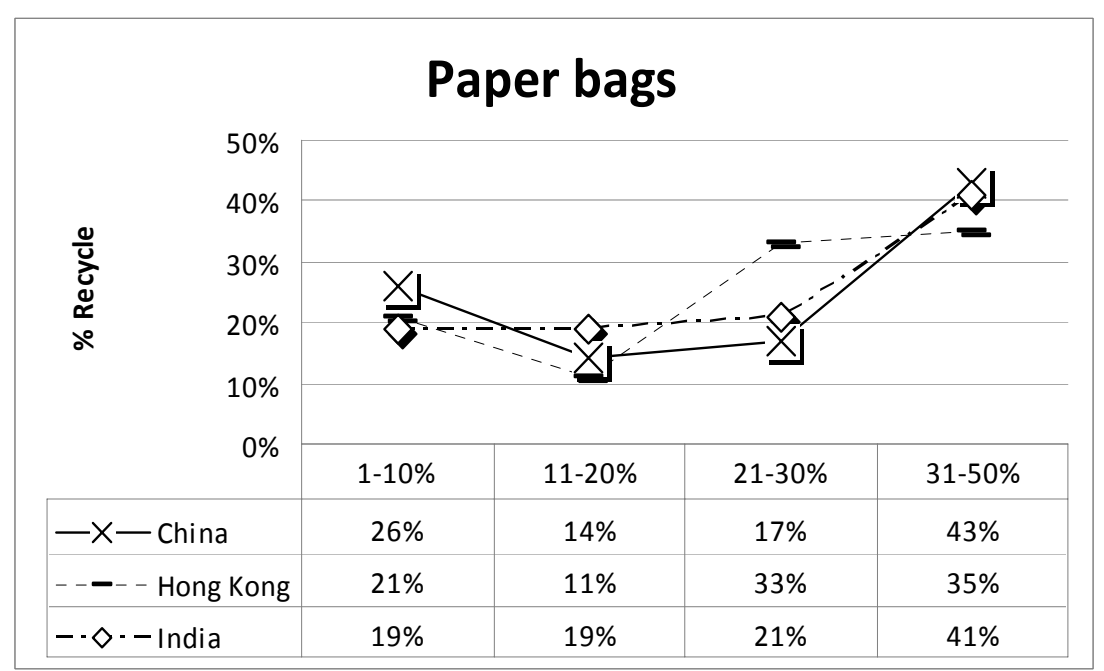

Figure 12. Percentage of recycling of paper bags 


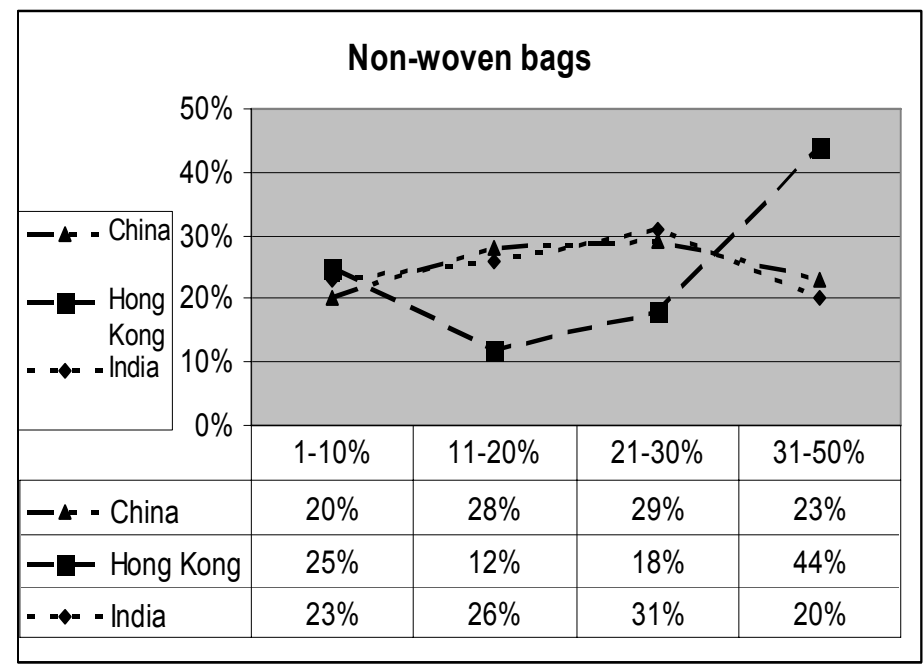

Figure 13. Percentage of recycling of non-woven bags

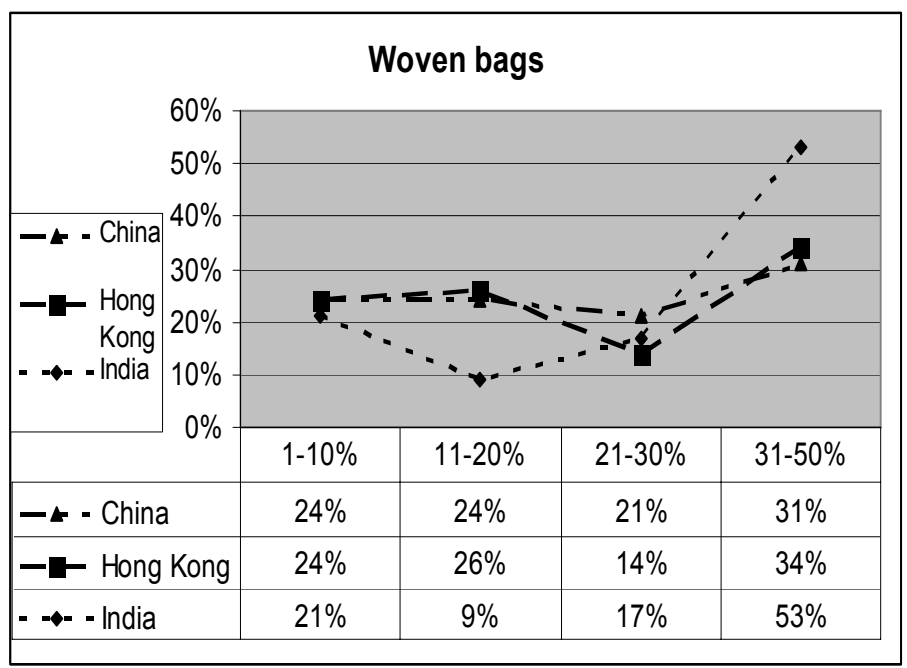

Figure 14. Percentage of recycling of woven bags

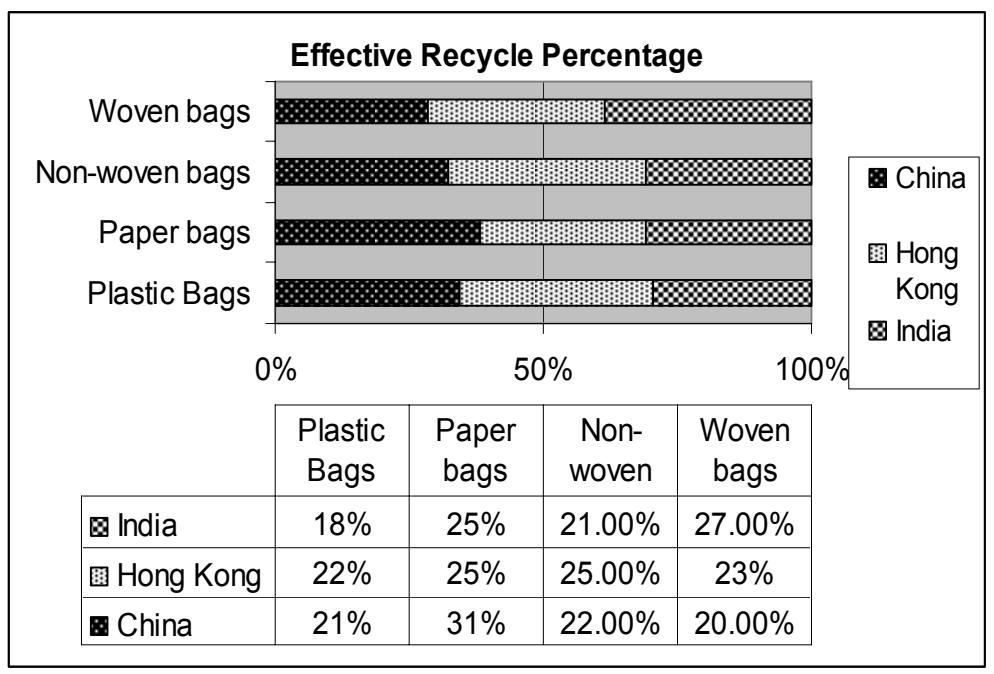

Figure 15. Effective recycling percentage 


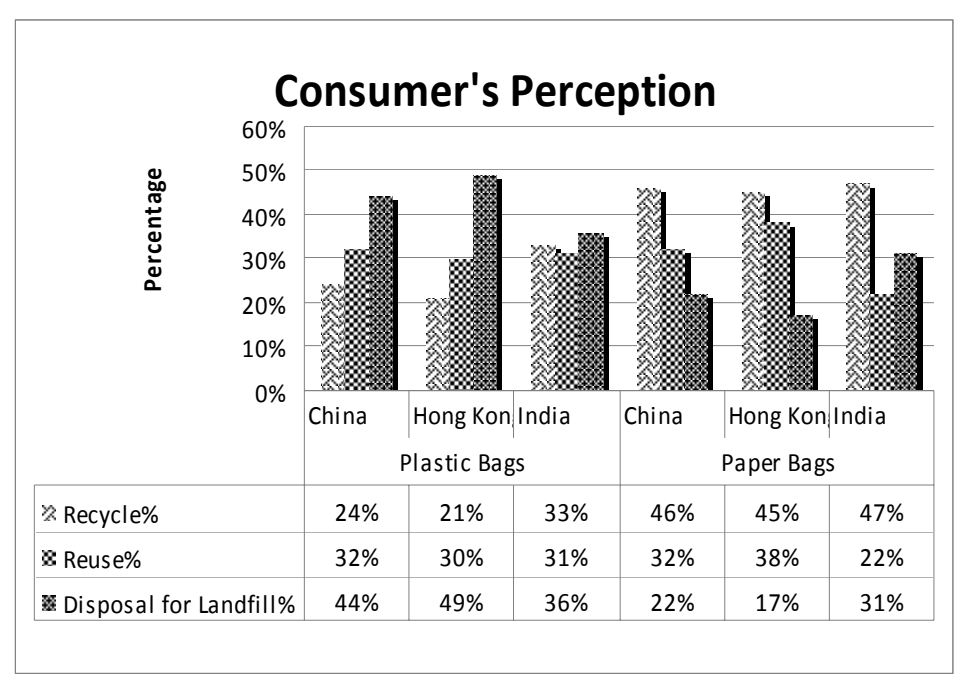

Figure 16. Percentage of plastic and paper bags that can be recycled/ reused/sent to landfill

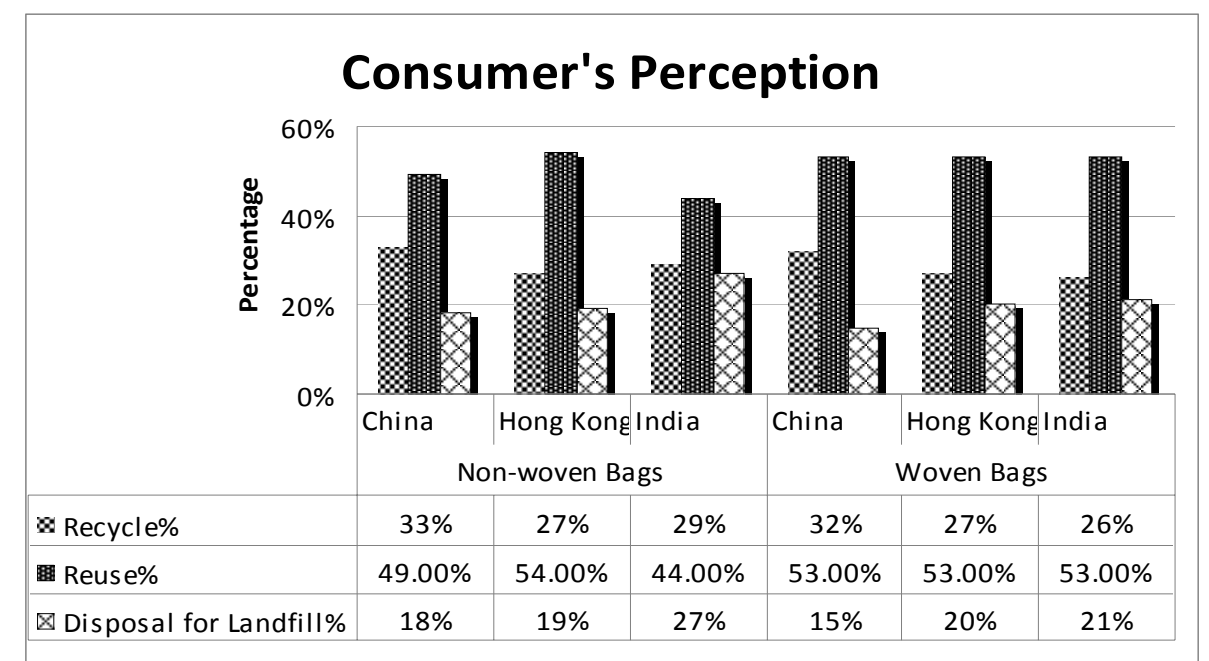

Figure 17. Percentage of non-woven and woven shopping bags that can be recycled/ reused/sent to landfill

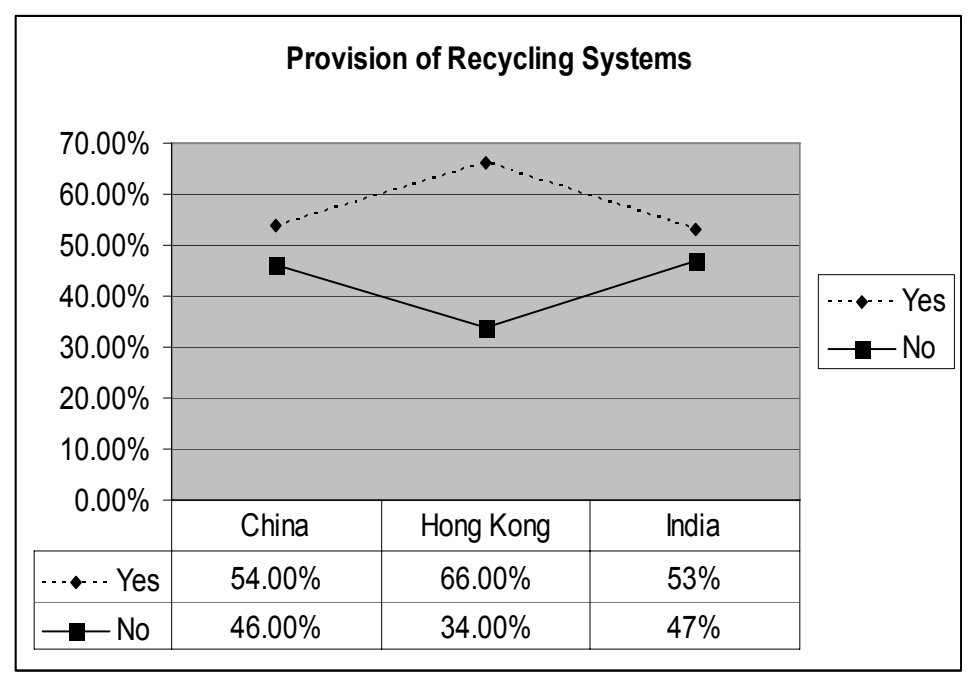

Figure 18. Provision of recycling systems 


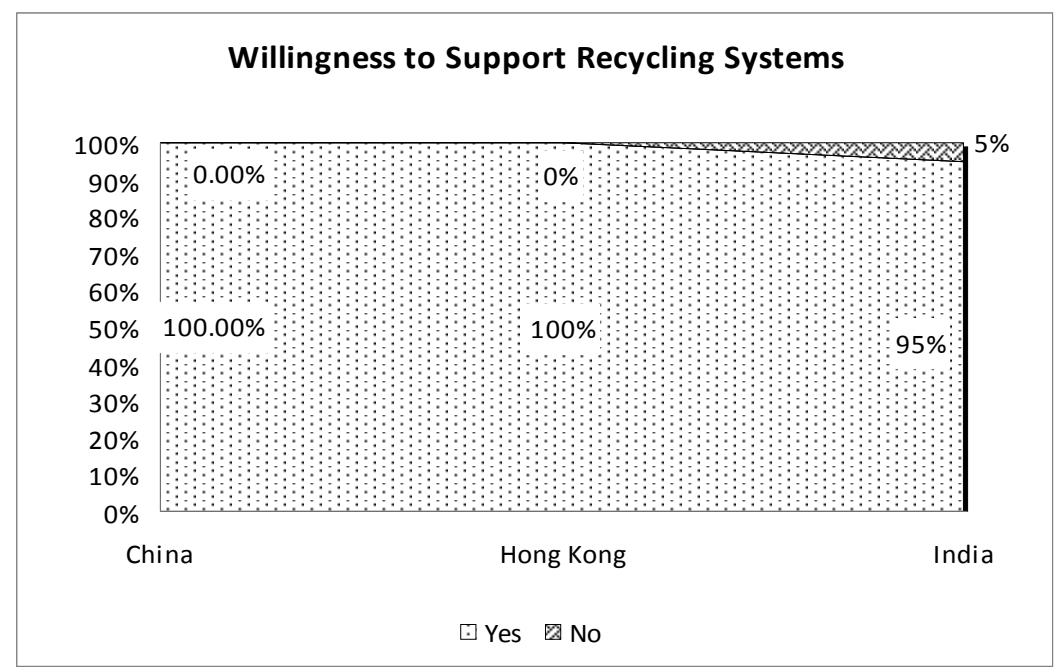

Figure 19. Willingness to support recycling systems

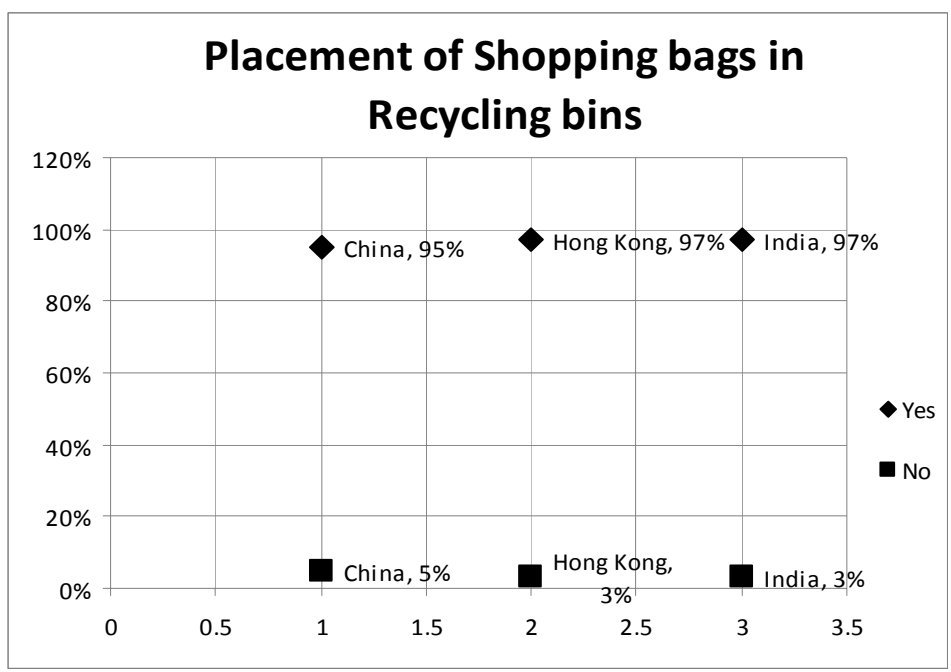

Figure 20. Placement of shopping bags in recycling bins 